\title{
ТЕХНОЛОГИЧЕСКИЕ СПОСОБЫ ПОВЫШЕНИЯ ЭФФЕКТИВНОСТИ ПЬЕЗОЭЛЕКТРИЧЕСКИХ МАТЕРИАЛОВ, ПРЕДНАЗНАЧЕННЫХ ДЛЯ МНОГОСЛОЙНЫХ ПРЕЦИЗИОННЫХ АКТЮАТОРОВ
}

\author{
М.А. Мараховский, А.Е. Панич, В.А. Мараховский
}

Научное конструкторско-технологическое бюро «Пьезоприбор» Южного федерального университета, ул. Мильчакова, 10, Ростов-на-Дону, Российская Федерация, 344090

E-mail: marmisha@mail.ru,panich@sfedu.ru,demuer@mail.ru

В данной статье исследована возможнность создания высокоэффективного полифазного пьезокерамического материала композиционного типа для применения в актюаторах прецизионного перемещения. Цель работы заключалась в получении пьезокерамического материала с оптимальной совокупностью характеристик на основе двух сегнетоэлектрических составов. Задача исследования состояла в апробации спекания полученного пьезокерамического материала методом консолидированного спекания. Эффективность полученного материала опробована на многослойных актюаторах.

Ключевые слова: пьезокерамический материал, многослойный актюатор, горячее прессование, микроструктура, электрофизические параметры, полифазный пьезокерамический материал

\section{TECHNOLOGICAL METHODS FOR IMPROVING THE EFFICIENCY OF PIEZOELECTRIC MATERIALS INTENDED FOR MULTILAYER PRECISION ACTUATORS}

\author{
M.A. Marakhovskiy, A.E. Panich, V.A. Marakhovskiy
}

Russia, Scientific Design and Technological Bureau "Piezopribor" Southern Federal University, Milchakova st., 10, Rostov-on-Don, Russian Federation, 344090

E-mail: marmisha@mail.ru,panich@sfedu.ru,demuer@mail.ru

In this article, the possibility of creating a highly efficient multiphase piezoceramic composite material for use in precision displacement actuators is investigated. The aim of the work was to obtain a piezoceramic material with optimal characteristics based on two ferroelectric compositions. The objective of the study was to test the sintering of the obtained piezoceramic material by the consolidated sintering method. The efficiency of the obtained material was tested on multilayer actuators.

Key words: piezoceramic material, multilayer actuator, hot pressing, microstructure, electrophysical parameters, polyphase piezoceramic material

Для цитирования:

Мараховский М.А., Панич А.Е., Мараховский В.А. Технологические способы повышения эффективности пьезоэлектрических материалов, предназначенных для многослойных прецизионных актюаторов. Рос. хим. ж. (Ж. Рос. хим. об-ва). 2021. T. LXV. № 4. C. 31-35

For citation:

Marakhovskiy M.A., Panich A.E., Marakhovskiy V.A. Technological methods for improving the efficiency of piezoelectric materials intended for multilayer precision actuators. Ros. Khim. Zh. 2021. V. 65. N 4. P. 31-35

\section{ВВЕДЕНИЕ}

На сегодняшний день активно развивающимся направлением микромеханики является создание актюаторов прецизионного перемещения на основе пьезокерамических преобразователей. Конструкция многослойного пьезоэлектрического актюатора является наиболее распространённой за счет целого ряда преимуществ: низковольтного 
управляющего напряжения (ниже 200 В), значительного создаваемого усилия (100 кгс), быстродействия (10 мкс), долговечности ( $10^{11}$ циклов), высокого коэффициента электромеханического преобразования $\left(\mathrm{k}_{33}=0,7\right)[1-3]$.

\section{ОСНОВНАЯ ЧАСТЬ}

Технология изготовления многослойных актюаторов основана на пакетной сборке тонких слоев плёнки из пьезоэлектрического материала, между которыми наносится формирующая электрод паста. После этого собранный пакет спекается при температуре спекания керамики, образуя высокопрочный монолитный актюаторный блок. Основным препятствием при изготовлении является задача согласования температур спекания керамических слоёв и вжигания формирующей электрод пасты.

Большинство пьезокерамических материалов характеризуются чрезмерно высокими температурами спекания (свыше $1200{ }^{\circ} \mathrm{C}$ ), не подходящими для вжигания формирующих электрод паст на основе $\mathrm{Ag}-\mathrm{Pd}$ (температура вжигания $900-$ $\left.1100{ }^{\circ} \mathrm{C}\right)$ и требующими применения других паст. Существующие пьезокерамические материалы с пониженными температурами спекания, как правило, обладают низкой эффективностью электромеханического преобразования $[4,5]$.

Таким образом, актуально создание пьезоэлектрических материалов с сочетанием высокой эффективности преобразования и пониженными температурами спекания. Такие характеристики можно реализовать в полифазных пьезоэлектрических материалах композиционного типа, представляющих собой совокупность двух или более сегнетоэлектрических фаз. Такого рода полифазные материалы принадлежат к гетерогенной морфотропной области, характеризующейся повышенной внутренней энергией вызванной физико-химическим взаимодействием исходных фаз [6, 7].

С целью создания полифазного материала использовалась сложная комбинация двух составов сегнетоэлектрических материалов

x Pb Ti $i_{0,35} \mathrm{Zr}_{0,21}\left(\mathrm{Zn}_{1 / 3} \mathrm{Nb}_{2 / 3}\right)_{0,14}\left(\mathrm{Ni}_{1 / 3} \mathrm{Nb}_{2 / 3}\right)_{0,13} \mathrm{O}_{3}+$ $+(1-\mathrm{x}) \mathrm{Pb}_{0,95} \mathrm{Sr}_{0,05} \mathrm{Ti}_{0,45} \mathrm{Zr}_{0,53} \mathrm{Cd}_{0,01} \mathrm{~W}_{0,01} \mathrm{O}_{3}$,

где значение х варьировалось от 0,2 до 0,8 . Оба сегнетоэлектрических материала имели структуру типа перовскита. Синтез каждой из фаз проводился в рамках метода твердофазных реакций. Режимы помола частиц в планетарной мельнице каждой из сегнетофаз подбирались с учётом требований их близкого гранулометрического состава,

во избежание различных скоростей рекристаллизации частиц разного радиуса кривизны [7-9].

$950^{\circ} \mathrm{C}$
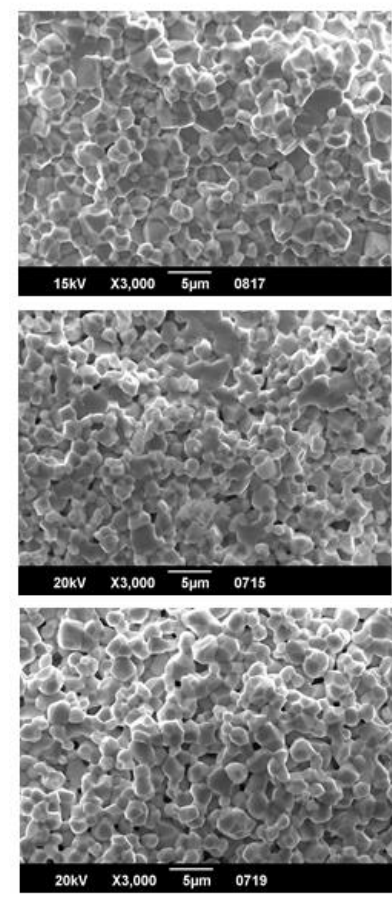

Рис. 1. Микроструктура пьезокерамических элементов из полифазного материала композиционного типа при значениях $\mathrm{X}=0,2 ; 0,5 ; 0,8$

На основе данных рентгенофазового анализа установлено, что в рамках области вариации составов сегнетоэлектрических материалов не происходит изменения их характера - материалы остаются гетерогенными, т.е. принадлежат к полифазным материалам композиционного типа. Существенного изменения микроструктуры керамики также не обнаружено.

Полученные в результате исследования значения электрофизических (ЭФП) и механических параметров (МП) (относительная диэлектрическая проницаемость - $\varepsilon_{33}{ }^{\mathrm{T}} / \varepsilon_{0}$, пьезоэлектрический модуль - $\mathrm{d}_{33}$, механическая добротность Q) указывают на эффективность предлагаемого приёма в части возможности управления совокупностью свойств пьезокерамического материала (рис. 2).

Анализ представленных данных позволяет утверждать, что оптимальной совокупностью ЭФП обладает состав со значением $\mathrm{X}=0,7$, соответствующий так называемому центру гетерогенной морфотропной области. Пьезокерамические элементы, указанного состава имеют максимальные значения плотности, коэффициентов электромеханической связи, продольного и поперечного пьезомодуля и 
диэлектрической проницаемости при минимальных величинах $\operatorname{tg} \delta$ и $\mathrm{Q}_{\mathrm{m}}$, что говорит об их возможном применении в многослойных пьезокерамических актюаторах прецизионного перемещения.

С целью повышения технологичности изготовления, а также исследования возможности управления процессом формирования микроструктуры, пьезокерамические элементы из полифаз- ного материала композиционного типа при значении $\mathrm{X}=0,7$ были спечены методом одноосного «горячего прессования» (ГП) в диапазоне температур 850 - $980{ }^{\circ} \mathrm{C}$. Спекание методом ГП проводилось на установке горячего прессования «УССК-1».

Снимки микроструктуры керамических образцов полученных методами АТМ, ГП подтверждают возможность управления процессом формирования мелкозернистой структуры керамики (рис. 3).

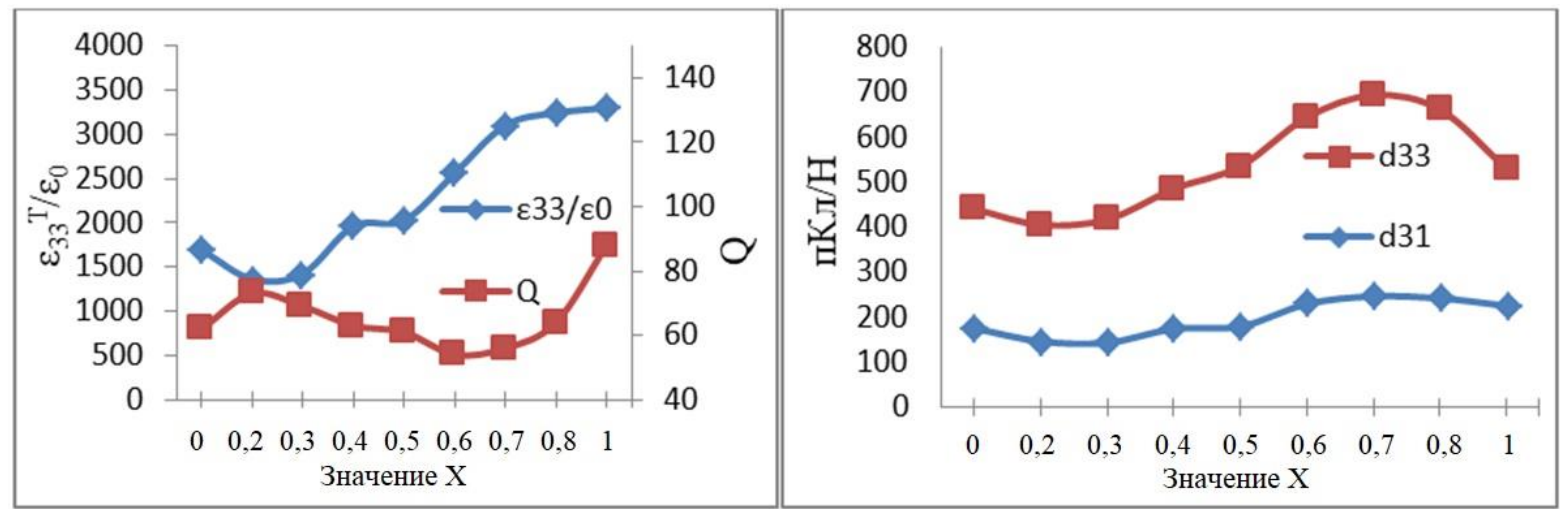

Рис. 2. Зависимость значений ЭФП и МП от состава полифазного материала, спечённых при $980{ }^{\circ} \mathrm{C}$

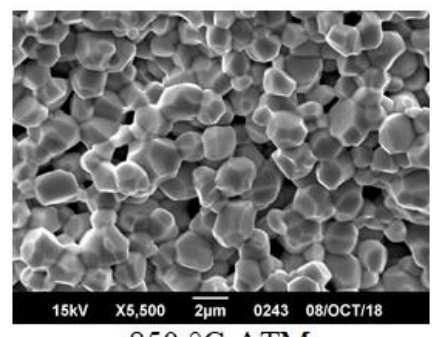

$850{ }^{\circ} \mathrm{C}$ ATM

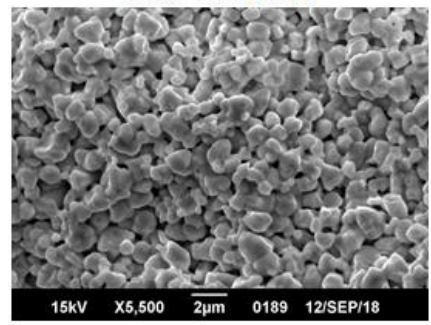

$850{ }^{\circ} \mathrm{C} \Gamma \Pi$

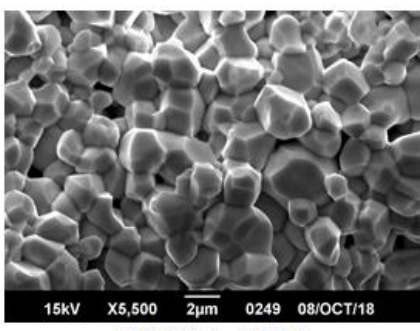

$900{ }^{\circ} \mathrm{C}$ ATM

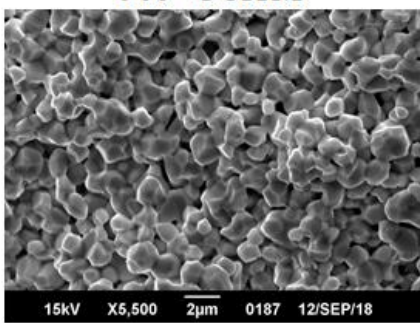

$900{ }^{\circ} \mathrm{C} \Gamma \Pi$

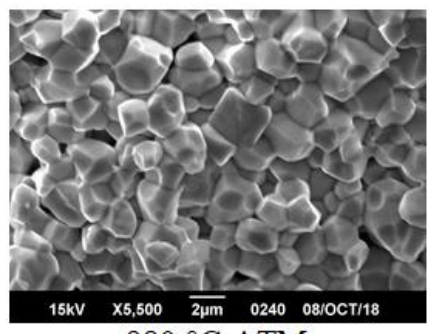

$980{ }^{\circ} \mathrm{C}$ ATM

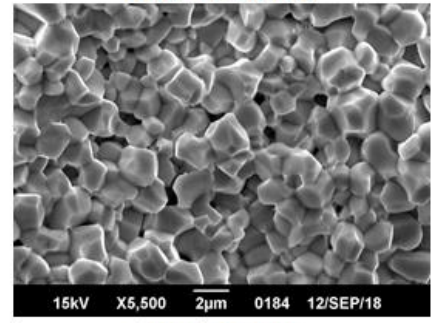

$980{ }^{\circ} \mathrm{C} \Gamma \Pi$

Рис. 3. Микроструктура полифазных пьезокерамических образцов композиционного типа при значении $\mathrm{X}=0,7$, полученных методами спекания АТМ и ГП

Плотная керамическая структура формируется уже при температуре спекания $850{ }^{\circ} \mathrm{C}$. C повышением температуры спекания наблюдается рост плотности керамики, при практически неизменных размерах зерен, что объясняется подавлением процесса вторичной рекристаллизации (при $\left.980^{\circ} \mathrm{C}\right)[10]$. Применяя метод ГП, температуру спекания пьезокерамических образцов удалось снизить до $900{ }^{\circ} \mathrm{C}$. Данные рентгенофазового анализа подтвердили неизменность фазового состава всех образцов, независимо от метода спекания.
Графики зависимостей плотности и ЭФП полифазных пьезокерамических материалов, полученных методом АТМ, ГП от температуры спекания представлены на рис. 4. Пьезокерамические элементы полученные методом ГП обладали повышенными свойствами (механическими и электрофизическими) по сравнению с пьезокерамическими элементами спечёнными традиционным спеканием АТМ. Такие повышенные свойства пьезокерамических элементов формируются при ГП уже на $900{ }^{\circ} \mathrm{C}$, что на $80^{\circ} \mathrm{C}$ ниже, чем при АТМ. 


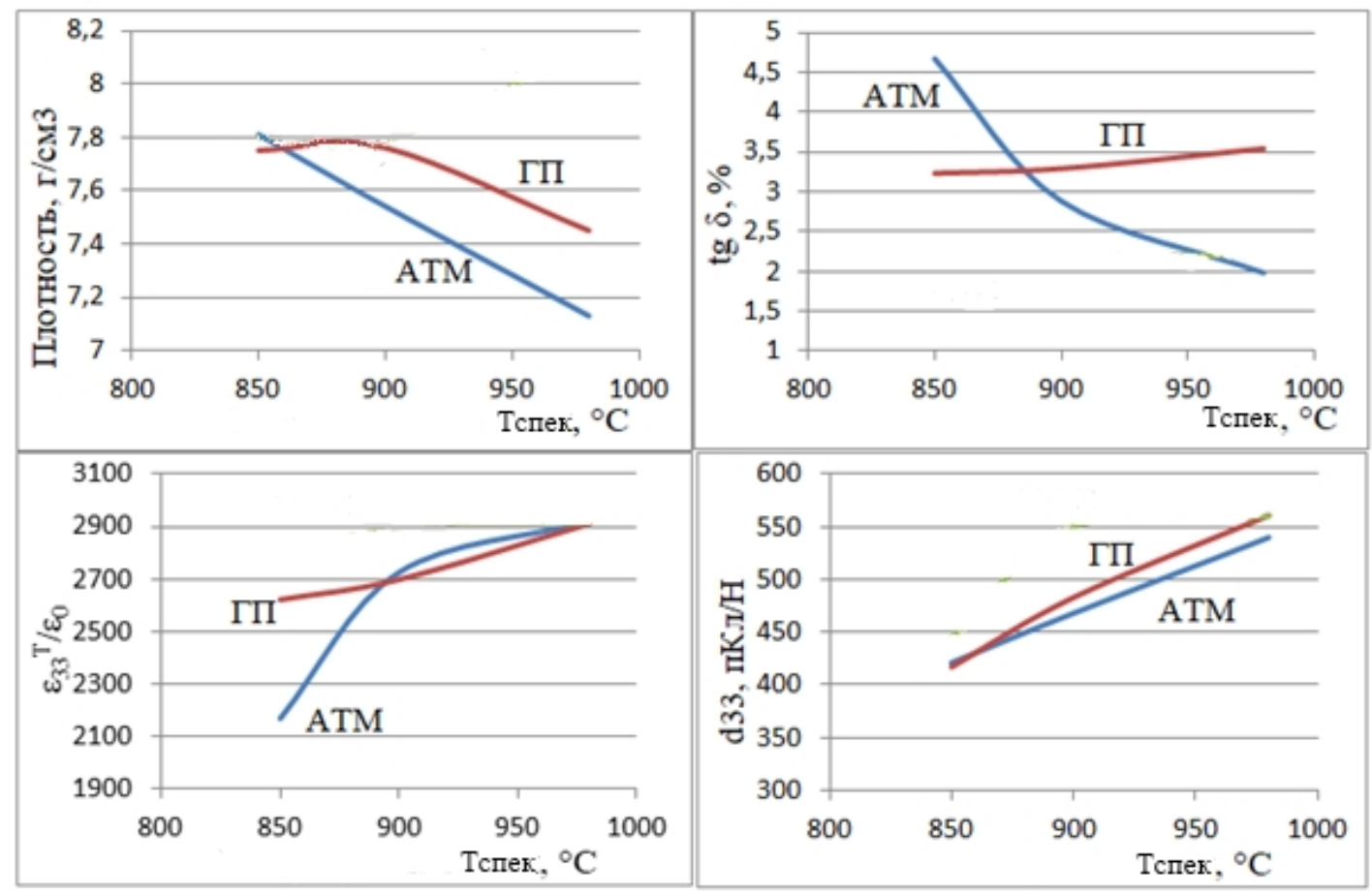

Рис. 4. Графики зависимостей параметров полифазного пьезоэлектрического материала при значении $\mathrm{X}=0,7$, полученных методами АТМ, ГП от температуры спекания

Из полученного полифазного материала композиционного типа при значениях $\mathrm{X}=0,7$ были изготовлены пакетные многослойные актюаторы (рис. 5). Такие актюаторы содержали от 20 - до 40 тонких слоев пьезокерамической пленки, между которыми наносилась формирующая электрод паста. Спекание многослойных актюаторов происходило при температуре $980{ }^{\circ} \mathrm{C}$, что позволило использовать для создания электродов пасту на основе $\mathrm{Ag}$ без добавок $\mathrm{Pt}$, тем самым сокращая расходы при производстве.

Максимальный ход многослойного актюатора при управляющем напряжении 100 В составил 1,5 мкм.

\section{ВЫВОДЫ}

В результате исследования установлено, что полученный полифазный пьезокерамический материал композиционного типа, благодаря сочетанию высокой эффективности электромеханического преобразования и низким температурам спекания (до $1000{ }^{\circ} \mathrm{C}$ ), отлично подходит для изготовления многослойных актюаторов. Эксперимен-

\section{ЛИТЕР А Т УР А}

1. Uchino K., Takahashi S. Multilayer ceramic actuators Current Opinion in Solid State and Materials Science. 1996. 1 (5). P. 698-705. тально изготовленные из указанного пьезокерамического материала многослойные актюаторы демонстрируют высокие эксплуатационные показатели, а также пониженную себестоимость. Изготовление полифазного пьезокерамического материала методом горячего прессования способствует оптимизации основных параметров и дополнительному понижению температуры спекания.

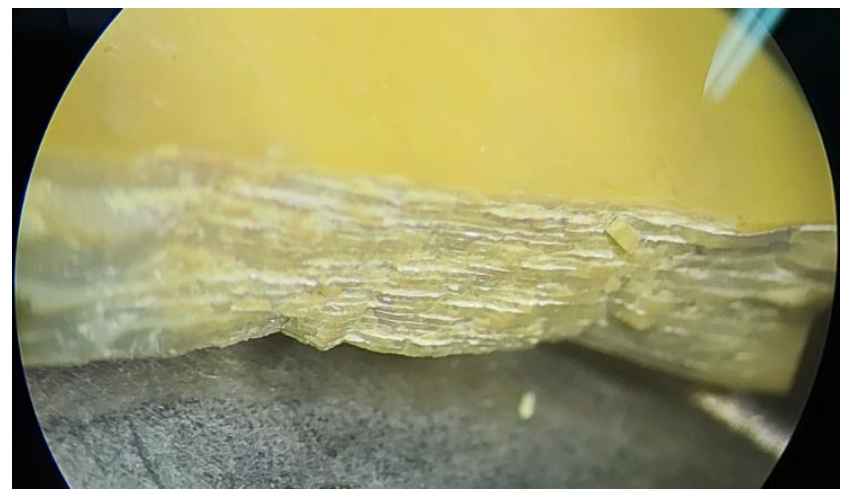

Рис. 5. Структура многослойного актюатора из полифазного материала композиционного типа

\section{REFERENCES}

1. Uchino K., Takahashi S. Multilayer ceramic actuators Current Opinion in Solid State and Materials Science. 1996. 1 (5). P. 698-705. 
2. Wang $Q$., Li F. A low-working-field $(2 \mathrm{kV} / \mathrm{mm})$, large-strain $(>0.5 \%)$ piezoelectric multilayer actuator based on periodically orthogonal poled PZT ceramics Sensors and Actuators, A: Physical. 2018. V. 272. P. 212-216.

3. Wang $Y$. Biomimetic moving mechanism with multilayer piezoelectric materials ACTUATOR 2018 - 16th International Conference. 2018. P. 412-415.

4. Еремкин В.В., Галий И.В., Нагаенко А.В., Панич А.А., Смотраков В.Г., Филиппов С.Е., Шилкина Л.А. Нано- и микросист. техн. 2012. № 6. С. 17.

5. Gromada M., Biglar M., Trzepiecinski T., Stachowicz F. Application of $\mathrm{BaTIO}_{3}$ perovskite material for piezoelectric multilayer actuators Lecture Notes in Electrical Engineering. 2018. V. 428. P. 29-35.

6. Третьяков Ю. Д. Твердофазные реакции. М.: Химия. $1978.360 \mathrm{c}$.

7. Кингери У.Д. Введение в керамику. М.: Изд. лит. по строительству, 1967. 500 с.

8. Патент РФ «Пьезокерамический материал для изготовления слоистых гетероструктур». RU 2552509 C2. Дата публикации: 10.06.2015.

9. Дельмон Б. Кинетика гетерогенных реакций. М. «Мир». $1972.554 \mathrm{c}$.

10. Мараховский М.А., Панич, А.Е., Мараховский В.А. Влияние технологии спекания на свойства сегнетожесткой керамики системы ЦТС. Технологии и материалы для экстремальных условий. Агой. 2019. 343 с.
2. Wang $Q$., Li F. A low-working-field $(2 \mathrm{kV} / \mathrm{mm})$, large-strain $(>0.5 \%)$ piezoelectric multilayer actuator based on periodically orthogonal poled PZT ceramics Sensors and Actuators, A: Physical. 2018. V. 272. P. 212-216.

3. Wang $Y$. Biomimetic moving mechanism with multilayer piezoelectric materials ACTUATOR 2018 - 16th International Conference. 2018. P. 412-415.

4. Eremkin V. V., et. al., Low-temperature sintering of piezoceramics of the PZT system intended for monolithic multilayer actuators. Nano - and microsyst. Tech. 2012. 6. p.17.

5. Gromada M., Biglar M., Trzepiecinski T., Stachowicz F. Application of $\mathrm{BaTIO}_{3}$ perovskite material for piezoelectric multilayer actuators Lecture Notes in Electrical Engineering. 2018. V. 428. P. 29-35.

6. Tretyakov Yu. D. Solid-phase reactions. Chemistry. 1978. $360 \mathrm{p}$.

7. Kingeri $U$. D. Introduction to ceramics. Publishing house lit. on construction, $1967.500 \mathrm{p}$.

8. Patent of the Russian Federation "Piezoceramic material for the manufacture of layered heterostructures". RU 2552509 C2. Date of publication: 10.06.2015.

9. Delmon B. Kinetics of heterogeneous reactions. Mir. 1972. $554 \mathrm{p}$.

10. Marakhovsky M. A., et. al., Influence of sintering technology on the properties of ferroflex ceramics of the CTS system. Technologies and materials for extreme conditions. 2019. $343 \mathrm{p}$.

Поступила в редакииюю (Received) 01.08.2021

Принята к опубликованию (Accepted) 03.09.2021 